\title{
The Microstructure of Isichazamazwi SesiNdebele
}

\author{
Mandlenkosi Maphosa, Department of African Languages and Culture, \\ Midlands State University, Gweru, Zimbabwe (maphosam@msu.ac.zw / \\ phosaz_m@yahoo.co.uk) \\ and \\ Dion Nkomo, Department of Afrikaans and Dutch, Stellenbosch University, \\ Stellenbosch; and Multilingualism Education Project, Centre for Higher \\ Education Development, University of Cape Town, \\ Republic of South Africa (deeouf@yahoo.co.uk)
}

\begin{abstract}
This article analyses the microstructure of Isichazamazwi SesiNdebele. The analysis takes place on two levels: the level of availability of information and the level of accessibility of the available information to dictionary users. Data derived from two outreach exercises carried out to ascertain users' perspectives on the dictionary and their competence in using the dictionary is also scrutinised while the notion of user-friendliness and the general principles of dictionary-making form the framework within which the analysis is done.
\end{abstract}

Keywords: DICTIONARY, DICTIONARY INFORMATION, DICTIONARY STRUCTURE, MICROSTRUCTURE, MACROSTRUCTURE, DICTIONARY CULTURE, REFERENCE NEEDS, REFERENCE SKILLS, ACCESSIBILITY, USER-FRIENDLINESS

Opsomming: Die mikrostruktuur van Isichazamazwi SesiNdebele. Hierdie artikel ontleed die mikrostruktuur van Isichazamazwi SesiNdebele. Die ontleding vind op twee vlakke plaas: die vlak van die beskikbaarheid van inligting en die vlak van die toeganklikheid van die beskikbare inligting vir woordeboekgebruikers. Gegewens verkry van twee uitreikoefeninge uitgevoer om gebruikers se opvattings van die woordeboek en hul vaardigheid in die gebruik van die woordeboek vas te stel, is ook ondersoek, terwyl die begrip van gebruikersvriendelikheid en die algemene beginsels van woordeboekmaak die raamwerk vorm waarbinne die ontleding gedoen word.

Sleutelwoorde: WOORDEBOEK, WOORDEBOEKINLIGTING, WOORDEBOEKSTRUKTUUR, MIKROSTRUKTUUR, MAKROSTRUKTUUR, WOORDEBOEKKULTUUR, NASLAANBEHOEFTES, NASLAANVAARDIGHEDE, TOEGANKLIKHEID, GEBRUIKERSVRIENDELIKHEID

\section{Introduction}

This article analyses the microstructure of Isichazamazwi SesiNdebele (henceforth the ISN) to evaluate the accessibility levels of information and the user-friendliness of the dictionary in this respect. Svensén (1993: 210) describes the microstructure as "the structure of individual dictionary entries: ${ }^{\dagger}$ their various parts 
and the mutual relationship of these including the typographical conventions used". It is one of the guide or access structures defined by Louw (1999: 108, $109)$ as "the set of structures that provides a framework within which the availability and accessibility of information can be evaluated". The others are the macrostructure and the mediostructure. Since the microstructure operates within a dictionary article, this evaluation is concerned with the provision, presentation and arrangement of data categories that constitute an entry.

The provision of information should satisfy users' needs. Gouws (1996: 100) notes that the aim of any lexicographic project should be the production of dictionaries which satisfy the needs of the target users of a specific language community. Hartmann (1996: 102) expresses a similar sentiment when he says that the ultimate reason for the existence of dictionaries is the users' need for information. In line with this view, this article looks at the provision of information through the ISN microstructure against the users' reference needs.

However, Svensén (1993: 10) adds another aspect to the above when he writes: "Not merely information needs of different categories of users are important. An equally important factor is their ability to find and make use of the information given." This then necessitates the investigation of the reference skills of the users. The article considers whether, in addition to the provision of various information categories, the microstructure of the ISN facilitates users' access to information.

Also of importance is the dictionary culture. The term dictionary culture according to Hartmann and James (1998), refers to: "The critical awareness of the value and limitations of dictionaries and other reference works in a particular community." The dictionary culture of a community gives information on both the users' reference needs and their reference skills. As such, it is also important to shed light on the dictionary culture of the Ndebele community which should be borne in mind when looking at the reference needs and reference skills of this community.

The analysis conducted in this article is based on two fieldwork exercises in the Ndebele-speaking communities: a feedback outreach exercise by the editorial team (Maphosa included) in 2002 and another by Nkomo in 2003. The ISN editors solicited users' perspectives on the dictionary, including its structure (Maphosa 2003), while Nkomo (2003) evaluated the accessibility of the dictionary, mainly focusing on the microstructure. The two exercises provided empirical data on the reference needs, reference skills and dictionary-using culture of the Ndebele community. In this respect the analysis of the ISN microstructure and the final assessment of the dictionary are performed in the light of dictionary research.

The article presents the ISN microstructure first. The reference needs of the Ndebele community, followed by their reference skills are then presented so that the ISN microstructure is judged in terms of the provision and accessibility of information. The dictionary-using culture of the Ndebele community is then presented in order to contextualise the assessment of the user-friendliness of the ISN in respect of its microstructure. 


\section{The ISN Microstructure}

The structure of any dictionary, be it the microstructure, the macrostructure, the mediostructure or even the megastructure, is largely determined by, among other factors, the type of dictionary, its purpose and the target users. If this line of argument is followed, it is therefore necessary to understand the dictionary itself in accordance with these factors before any attempt at judging its structure is made. In the case of the ISN, its type, its purpose, and its main target users should be defined.

The ISN is a monolingual general-purpose dictionary and its target users are mainly secondary schools, tertiary institutions and the general Ndebele speakers. Coming after A Practical Ndebele Dictionary, a bilingual English-Ndebele dictionary by Pelling (1966), it is the first monolingual dictionary in Ndebele.

The ISN has a general microstructure. Béjoint (2000) identifies two distinct types of microstructure, a general and a specialised. A general microstructure gives a "complete" programme of information in each article, including at least an explanation of the meaning, generally with the help of a definition (Béjoint 2000: 38). In addition to definitions, a general microstructure also includes other information categories like parts of speech, pronunciation, examples, etymology, etc.

The above description suits the ISN microstructure as dictionary articles contain a number of information categories, including information on spelling, variants, type of speech, meaning, word usage (examples), and synonyms. It does not have a specialised microstructure since it is not restricted to and characterised by a single information category like etymology or synonyms. Table 1 presents the information categories that constitute the ISN microstructure and the lexicographic conventions used to present them. Appendix 1 is a page extracted from the dictionary to complement Table 1.

Table 1: ISN information categories and conventions used

\begin{tabular}{|l|l|}
\hline \multicolumn{1}{|c|}{$\begin{array}{c}\text { Information } \\
\text { Category }\end{array}$} & \multicolumn{1}{c|}{ Presentation and Conventions used } \\
\hline Spelling & Headwords in bold print \\
\hline Variants & After headwords, upper case and in [ ] and BONA \\
\hline Type of speech & After headwords, through abbreviations, e.g. bz 5, sz mwa \\
\hline Meaning & Definitions as full sentences, sense numbers used \\
\hline Examples & After definitions and in italics \\
\hline Synonyms & After explanations through abbreviation FAN \\
\hline
\end{tabular}

From Table 1 and Appendix 1 it may be noted that headwords are keys to dictionary articles. Bold print and the indention of other information categories in the successive lines make them distinct and easy to identify. In addition, as 
Landau (2001: 112) stresses, headwords are "indicators of the preferred spelling". Their variants, if any, are presented immediately after them, printed in upper case letters and enclosed in square brackets. Variants present alternative forms of the word with regard to spelling and are defined using the main articles.

Speech-type information is then given by means of abbreviations, with the dominant ones being $b z$ for ibizo (noun) and $s z$ for isenzo (verb) as the majority of dictionary lemmata fall within these two word categories. Nouns are then marked for class, e.g. bz 5 for nouns falling in class 5 following the Bantu noun classification system by Meinhof in terms of prefixes, while verbs are marked for transitivity and intransitivity using the abbreviations mwa and gmwa for isenzo esilomenziwa and esingelamenziwa respectively.

So far the presentation of formal and syntagmatic information categories has been described. The remaining types are basically semantic although others tend to overlap. Definitions are the most important of all semantic categories. In the ISN, definitions are given as full sentences with the headword being used in the definition. This follows one of the defining principles of the Collins Birmingham University International Language Database (COBUILD), whose main objective is to make definitions as comprehensive as possible. When a word carries at least two senses, a definition is provided for each sense with the primary sense presented first. In such instances the definitions are distinguished by sense numbers, with 1 for the primary sense, 2 for the second sense, etc. In some instances, definitions in the ISN are elucidated by means of examples. Printed in italics, examples illustrate the usage of the word, that is, its combination with other words in speech. Then lastly, synonyms are given after the abbreviation FAN for amagama alengcazelo efanayo. For space economy, lesser synonyms are defined by major synonyms.

\section{ISN User Perspectives}

User perspective considers a lexicographic work from the point of view of the user. In this case, focus is on the users' reference needs, the users' reference skills, and the dictionary culture which determines users' reference needs and reference skills.

\subsection{The ISN Users' Needs}

According to Hartmann (1983: 5), "all dictionaries are motivated by and judged against the lexical needs of the language user whom they serve". An analysis of the microstructure should therefore look at the provided information categories relative to users' needs.

The ISN editorial team managed to solicit the ISN users' needs from Ndebele dictionaries. According to Maphosa (2003: 6), "users were given a number of information categories and ... asked to state whether they had need for them 
in dictionaries or not". Some information categories investigated are not provided in the ISN, but were included so as not to limit users to what is found in the dictionary, thereby giving them the possibility to express their needs, if at all, for the excluded categories. Furthermore, some of the information categories omitted from the ISN need to be considered for the Advanced Ndebele Dictionary. The need for information was also investigated with regard to English dictionaries. Since English dictionaries seem to be an integral part of the dictionary-using culture in the Ndebele community, this was done with the expectation that the findings could reveal interesting trends in users' needs. The influence of English dictionaries on users' needs and reference skills should not be underestimated. Table 2 sums up the ISN users' lexicographic needs obtained by the editorial team through the outreach exercise.

Table 2: Comparative figures on users' needs in Ndebele and English dictionaries.

\begin{tabular}{|l|c|c|c|c|c|}
\hline $\begin{array}{c}\text { Information } \\
\text { categories }\end{array}$ & $\begin{array}{c}\text { Total number } \\
\text { of informants }\end{array}$ & \multicolumn{2}{c|}{$\begin{array}{c}\text { Ndebele } \\
\text { dictionaries }\end{array}$} & \multicolumn{2}{c|}{$\begin{array}{c}\text { English } \\
\text { dictionaries }\end{array}$} \\
\hline & & + & - & + & - \\
\hline Meaning & 1250 & 425 & 825 & 1250 & 0 \\
\hline Spelling & 1250 & 1100 & 150 & 1250 & 0 \\
\hline Examples & 1250 & 1150 & 100 & 1196 & 54 \\
\hline Speech type & 1250 & 850 & 400 & 1212 & 38 \\
\hline Synonyms & 1250 & 775 & 475 & 1110 & 140 \\
\hline Variants & 1250 & 900 & 350 & 1150 & 100 \\
\hline Etymology & 1250 & 980 & 270 & 1035 & 215 \\
\hline Pronunciation & 1250 & 455 & 795 & 1072 & 178 \\
\hline Tone & 1250 & 320 & 930 & 220 & 1030 \\
\hline
\end{tabular}

Key: $\quad+$ need for information category

- no need for information category

A comparison of Table 1 on information categories provided in the ISN and Table 2 on the ISN reference needs shows that the ISN is deficient in meeting the reference needs of the users. Svensén (1993) is of the view that decisions on lexical treatment of lemmata in terms of provision and presentation of information should be in the order of the preference of the intended users. However, as the ISN is the first and so far the only monolingual Ndebele dictionary, this could not have served as a guide for the ISN editorial team when the dictionary was compiled. The dictionary was largely shaped, according to the description of Béjoint (2000: 170), by "what lexicographers knew, imagined, of those needs, and by what lexicographers knew about the language in general and words in particular". The comment on whether or not the editors' decisions were justified shall therefore be reserved until the genuineness of the reference needs of the ISN users is confirmed in view of the Ndebele dictionary culture. 
An analysis of the findings of the ISN editorial team on users' needs presents a negative view of the Ndebele dictionary culture. The target users seem to be unaware of the value of dictionaries in Ndebele as becomes evident from the lower rates of the need for information categories compared to those from English dictionaries, with the worst being the need for meaning which is rated at only $36 \%$.

Dictionaries are largely consulted for the meaning of words, and if the target users of a dictionary do not recognise the value of this important information category, then it means that they are unaware of the value of the dictionary itself. Interesting though is that the very same users, who claim not to need meaning from the Ndebele dictionary indicate a higher need for other information categories such as spelling, speech type, etymology, variants, synonyms and examples. Except in specialised dictionaries with specialised microstructures, these information categories cannot be separated from the meanings of words. In most cases, some of them complement the explanation of the words given by definitions. For instance, examples of word usage usually elucidate the meaning of a word and therefore a user who searches for the meaning of the word, will need to learn it from the examples of word usage.

A higher need for examples of word usage somehow reflects a genuine, but unacknowledged need for word meanings by ISN users. In respect of this view, it may be noted that these claims are merely a manifestation of attitude problems characteristic of a community with a young dictionary culture, which holds that people know their language and need no explanation of it. When Nkomo (2003) undertook a control test that involved assigning students in four Bulawayo high schools selected words to define, this attitude surfaced among them. The number of students who acknowledged the need for meaning from Ndebele dictionaries rose as many who had denied this need failed the test. Hadebe (2004: 98-99) explains the detrimental impact of attitude problems on reference needs, dictionary culture and reference skills. The users' perspectives on the information provided by the ISN, and their needs should therefore be treated with caution.

\subsection{The ISN Users' Reference Skills}

Emphasising the importance of users' reference skills, Svensén (1993: 10) notes that the form of a dictionary should be greatly determined, among other factors, by the users' capabilities to decode the provided information. In addition to the investigation of users' needs, the reference skills of the ISN users were also investigated during the two field-work exercises. The participant-observation method was employed in both outreach exercises to discover the reference skills of students at secondary schools. The method was effective in affording the researchers an opportunity to observe the skills of users engaged in actually consulting the dictionary. The participants and informants were given the task to decode the information categories in the dictionary and interpret some of the 
conventions. The findings tabulated below are those of the ISN editors since they represent a bigger sample than those obtained from the schools.

Table 3: Users' capabilities to interpret conventions and decode information from the ISN.

\begin{tabular}{|l|r|r|}
\hline \multicolumn{1}{|c|}{ Convention } & \multicolumn{1}{c|}{+} & \multicolumn{1}{c|}{} \\
\hline Bold print & 1200 & 50 \\
\hline Italics & 987 & 263 \\
\hline Abbreviation bz & 933 & 317 \\
\hline Abbreviation sz & 918 & 332 \\
\hline FAN & 1100 & 150 \\
\hline BONA & 1210 & 40 \\
\hline Square brackets & 775 & 475 \\
\hline Sense numbers & 900 & 350 \\
\hline
\end{tabular}

Key: $\quad+$ correct interpretation of the convention

- wrong interpretation of the convention or no response

When the table is studied, it is safe to say that the ISN users possess an above average of the required reference skills in using the dictionary, although it is the first monolingual Ndebele dictionary, which they consulted. This may be attributed to the fact that users have at some time used English, and perhaps a few Zulu dictionaries. At this point, users' reference skills are not a serious problem in Ndebele dictionary use. Ilson (1984: 83) observes that "a dictionary is a social artefact ... whose users become familiar with its conventions unconsciously, just as lexicographers do". This is true of the ISN and its users who exhibited no difficulty in using the ISN in spite of it being the first monolingual Ndebele dictionary.

\subsection{Dictionary Culture in Ndebele}

By developing a dictionary culture as noted by Hartmann and James (1998), a community makes a considerable adjustment to lexicography. This means that the community acknowledges a gap in its linguistic knowledge and appreciates lexicography as a tool that may be exploited to fill this gap. This does not necessarily mean that the community waits for lexicographers to produce dictionaries. Rather, the community follows the dictionary-making trends closely, making sure that lexicographers produce good dictionaries. In a community with an advanced dictionary culture, users would criticise dictionaries and even reject some if they do not meet their lexicographic needs.

Svensén (1993) notes that the linguistic gap alluded to above, which necessitates the use of dictionaries is realised when writing, reading, speaking and/ 
or listening. These are daily activities which involve the use of language. What logically follows is that dictionaries have a vital role in peoples' everyday lives. In spite of this, a dictionary-using culture in the Ndebele community is still in its infancy. The community has not made a considerable adjustment to lexicography. Perhaps this is due to the fact that currently only three Ndebele dictionaries are available for use, namely Pelling's (1966) A Practical Ndebele Dictionary, which is bilingual, Hadebe's (2001) Isichazamazwi SesiNdebele, which is the only monolingual Ndebele dictionary, and Nkomo and Moyo's (2006) Isichazamazwi SezoMculo, which is a specialised Ndebele dictionary of musical terms.

One aspect relating to dictionary culture is dictionary ownership. Nkomo (2003) held eight discussions with students, with each discussion involving at least 25 Ndebele students at four high schools in Bulawayo. During the discussions, it emerged that only two out of at least two hundred students possessed a dictionary (none of these being the ISN). The rest of the students said they borrow dictionaries from school libraries, community libraries, friends or relatives. However, out of the four schools, only three had at least one ISN copy in their libraries although the majority of the students had not used it. The implications of this is that either the schools were unaware of the availability of the dictionary at bookshops two years after its publication or were not aware of the value of a Ndebele dictionary, hence their reluctance to buy it. This lack of awareness is therefore passed on to students and impacts negatively on the development of a dictionary culture. Interestingly, the schools were chosen on the basis that they produce the best Ndebele results at both ordinary and advanced levels annually. Therefore great awareness of language development activities in such schools would be expected.

Although the Ndebele community is not accustomed to Ndebele dictionaries, it has nevertheless used English dictionaries. Secondary school students could even name some English dictionaries they have consulted. The higher need for most of the information categories from English dictionaries as shown in Table 2 is part of the dictionary culture of the Ndebele community. However, the frequency of using dictionaries is very low, with most of the users consulting dictionaries only on rare occasions.

The above findings serve to confirm the infancy of a dictionary-using culture in the Ndebele community. The ISN users' reference needs and reference skills are a result of this culture. Whilst the method of measuring the reference skills might have been accurate, it should be noted that, with this dictionary culture, the reference needs could not be relied on either in compiling the dictionary or in passing a judgement on the provision of information in the dictionary. The reference needs should be treated with caution until the dictionary culture has been improved. Therefore a dictionary-using culture is a critical problem area for Ndebele lexicography, of which every form of dictionary criticism should be wary. In the light of this, the accessibility of information by means of the ISN microstructure, hence its user-friendliness, is evaluated in the next section. 
http://lexikos.journals.ac.za

\section{User-friendliness of the ISN Microstructure}

As stated earlier in the article, the ISN microstructure is evaluated on two levels. The first is that of meeting the reference needs of users by providing much needed information on words. The second is that of employing symbols to facilitate users' access to information without estranging them. The evaluation considers both the user perspective and the compiler perspective. Dictionaries are not only compiled according to the user perspective, but in accordance with lexicographic principles guiding this compilation. Therefore, while the ISN editors' efforts of meeting their target users' needs are investigated, their consistency in applying the principles of lexicography is not neglected.

Table 2 shows that only the last three information categories investigated are not provided in the ISN. As far as the excluded information is concerned, it should be remembered that no one dictionary is exhaustive of all aspects of a language. In the same manner, the ISN as a general dictionary could not satisfy all its target users, especially those whose needs were unknown, or could not be relied upon even if they were known because they are lexicographically unschooled and ill-informed.

The dictionary also reflects the trends in language study at the time of its compilation. At present, the study of Ndebele grammar has not reached advanced levels of analysis. For instance, mainly introductory courses of Ndebele grammar are offered at the University of Zimbabwe, Harare. Perhaps after a serious needs analysis, an advanced dictionary should provide some of the excluded information types. However, at the moment, the needs analysis for information shows that, with the improvement of users' awareness of the value of dictionaries, the dictionary can serve as a vital reference tool in Ndebele.

After deciding on the information the dictionary is to provide, the lexicographer further determines the conventions that will help him/her in presenting the information and at the same time help the user in accessing it. In section 3.2 , it was noted that the ISN users displayed above average skills in decoding information from the dictionary. What this means is that, while the conventions enabled the editors to save space, they are explicit enough to guide users to the various information categories the dictionary provides.

In addition to expecting users to learn how to use the dictionary on their own, lexicographers usually give guidelines in the front matter on how the microstructure presents information and directs users. The microstructure cannot be fully studied and be comprehensively understood in isolation (Nkomo 2003: 5). In the same way, users may need to refer to the front matter to obtain instructions with regard to the microstructure since it does not function in isolation; it is only part of the guide or access structures. To provide users with guidelines, the ISN editors explain the microstructure in the front matter which is detailed enough for easy comprehension. Hadebe et al. (2001: xl) note the need for guidance by saying: 
Kuqakathekile kosebenzisa isichazamazwi ukuthi alandele leziziqondiso ukuze athole lokho ayabe ekudinga. Lapha sichaza ngamafitshane impawu ezihamba legamanhloko. (It is important to the dictionary user to follow these guidelines so that it becomes easy to access the required information type. Here we briefly explain the markers accompanying each headword.)

However, it may be argued that information must be presented in a simple manner rather than expecting the user to read the front matter or interpret the keys. The provision of the front matter has always been a good lexicographic principle although dictionary users tend to ignore it. For instance, investigating the dictionary-using culture of the ISN users, Nkomo (2003: 53) discovered that the majority of students, who are the main target users of the ISN do not read the front matter. While this serves to emphasise the need for simplicity in the presentation of dictionary information, especially for users in a community where a dictionary-using culture is still in its infancy, at the same time, it calls for user education with regard to lexicography in general and other aspects of lexicography like, among others, dictionary structure in particular. Hadebe (2004: 89-104) reiterates the importance of teaching dictionary skills as a way of developing a dictionary-using culture in Ndebele and other communities who are in a similar situation.

The presentation of the information and the use of conventions should be done consistently for related headwords. This is accentuated by Zgusta (1971: 248) who points out that "all entries should be constructed in as uniform a way as possible". Consistency is important, for the user has to master the microstructure from the start to continue using the dictionary with efficiency. Such a structure, the microstructure in particular, in this way becomes effective for educating its users on how to use the dictionary. A closer look at the microstructure of the ISN (see Appendix 1) shows that the ISN editors have used the conventions in presenting dictionary information consistently. This is likely to be a score on the lexicographers' attempt to achieve more user-friendliness.

After the ISN users' needs, reference skills and the dictionary-using culture which informs them have been identified, a fair assessment of the dictionary in terms of accessibility and user-friendliness can be made. Firstly, it should be remembered that the ISN is a pioneering work in Ndebele monolingual lexicography whose shape was not dictated by the real users' needs, but "assumptions by dictionary editors" (Hadebe 2004: 90). Even the needs on which this article is based are questionable since at the time the research was undertaken (2002 and 2003), the majority of the users had not seen, let alone used the dictionary. In this respect, attention must be shifted from the provision of information and the satisfaction of users' needs to the accessibility of the provided information.

Here it should be remembered that accessibility of information does not necessarily mean a simple microstructure with easily interpretable conventions. According to Béjoint (2000: 157), the skills necessary for the successful consultation of a dictionary are only those of the average educated language 
user. When this view is accepted, it follows that if average secondary school Ndebele students could use the dictionary upon seeing it for the first time, it is accessible and user-friendly. Béjoint further compares the process of learning to use a dictionary to learning to read, a point which somehow emphasises the need for user-education rather than producing a dictionary outside the principles of dictionary-making. Children learn to read by receiving help or support from their educators. When the ISN microstructure is considered in relation to the ISN users' reference skills, an improved dictionary-using culture and practice will hopefully help and support more users to be more comfortable with the dictionary.

As a pioneering reference work in Ndebele monolingual lexicography, the ISN can even educate its users lexicographically. The consistency with which the microstructure presents information contributes towards users becoming used to the dictionary. In addition, the provision of a detailed and lexicographically educative front matter for a pioneering monolingual dictionary does not only help Ndebele language users in the consultation of the ISN, but also in introducing them to Ndebele lexicography. The conventions used in the ISN will be interpreted and used with greater ease and efficiency for the access of information in future Ndebele dictionaries.

\section{Conclusion}

The focus of this article has been on the ISN microstructure, assessing the accessibility of dictionary information and the user-friendliness of the dictionary. The assessment is based on the ISN users' reference needs in relation to the information types provided in the ISN and the ISN users' reference skills in relation to the lexicographic conventions used in presenting the provided information types. It emerges that a fair assessment could not be done without taking cognisance of the dictionary-using culture of the Ndebele community since it dictates both the users' reference needs and their reference skills. The dictionary-using culture of the community seems to be the most critical point that needs attention so that users can access the provided information in the ISN. What is vital is that they can fully utilise the information and hence see the value of a monolingual dictionary in their language. As for the provided information, the microstructure facilitates its access since, through it, users can reach the searched-for information types without any training. The consistent presentation of information is helpful for users who are not fully competent in using a monolingual dictionary in their own language, but with practice they are likely to learn quickly. This consistency is complemented by a detailed front matter which gives, among other aspects, a comprehensive explanation of the microstructure. In this regard, it can be concluded that the dictionary information is accessible and the dictionary itself is user-friendly, but the Ndebele community is not lexicographically well-cultured. 


\section{Note}

$\dagger \quad$ In accordance with Gouws and Prinsloo (2005: 15), among other metalexicographers, article/-s instead of entry/-ies will be used throughout this evaluation.

\section{References}

Béjoint, H. 2000. Modern Lexicography: An Introduction. Oxford/New York: Oxford University Press.

Gouws, R.H. 1996. A Sequence for Meeting Lexicographic Needs. Lexicography as a Financial Asset in Multilingual South Africa: 97-110. Pretoria: Department of Arts, Culture, Science and Technology.

Gouws, R.H. and D.J. Prinsloo. 2005. Principles and Practice of South African Lexicography. Stellenbosch: SUN PreSS.

Hadebe, S. 2004. Improving Dictionary Skills in Ndebele. Lexikos 14: 89-104.

Hadebe, S. et al. (Eds.). 2001. Isichazamazwi SesiNdebele. Harare: College Press.

Hartmann, R.R.K. 1983. On Theory and Practice: Theory and Practice in Dictionary-making. Hartmann, R.R.K. (Ed.). 1983. Lexicography: Principles and Practice: 3-11. London: Academic Press.

Hartmann, R.R.K. 1996. Lexicography as an Applied Linguistic Discipline. Hartmann, R.R.K. (Ed.). 1996. Solving Language Problems: From General to Applied Linguistics. Exeter: Exeter University Press.

Hartmann, R.K.K and G. James. 1998. Dictionary of Lexicography. London: Routledge.

Ilson, R.F. 1984. The Communicative Significance of Some Lexicographic Conventions. Hartmann, R.R.K. (Ed.). 1984. LEXeter '83 Proceedings. Papers from the International Conference on Lexicography at Exeter, 9-12 September 1983: 80-86. Tübingen: Max Niemeyer.

Landau, S.I. 2001. Dictionaries. The Art and Craft of Lexicography. Second Edition. New York/Cambridge: Cambridge University Press.

Louw, P.A. 1999. Access Structures in a Standard Translation Dictionary. Lexikos 9: 108-118.

Maphosa, M. 2003. The Users' Perspectives on Isichazamazwi SesiNdebele. Paper presented at the Eighth International Conference of the African Association for Lexicography, organised by the Department of Germanic and Romance Languages, University of Namibia, Windhoek, Namibia, 7-9 July 2003.

Nkomo, D. 2003. The Microstructure and the Accessibility of Dictionary Information: An Analysis of Isichazamazwi SesiNdebele. Unpublished B.A. Hons. Thesis. Harare: University of Zimbabwe.

Nkomo, D. and N. Moyo (Eds.). 2006. Isichazamazwi SezoMculo. Gweru: Mambo Press.

Pelling, J.N. 1966. A Practical Ndebele Dictionary. Harare: Longman Zimbabwe.

Svensén, B. 1993. Practical Lexicography: Principles and Methods of Dictionary-Making. Oxford: Oxford University Press.

Zgusta, L. 1971. Manual of Lexicography. The Hague: Mouton. 
Appendix 1: $\quad$ Page 124 of the ISN showing the structure of entries

\section{iKhalanga}

iKhalanga bz 5. IKhalanga ngumuntu wosendo lomhlobo wamaKhalanga okhuluma isiKhalanga njengolimi lwakhe lomdabuko.

ikhalathi bz 5. BONA ikharathi.

ikhalenda bz 5. Ikhalenda ngumbhalo otshengisa amalanga asenyangeni, lamaviki akhona njengokulandelana kwawo kulowo mnyaka.

ikhalikhuletha bz 5. Ikhalikhuletha ngumtshina omncane osetshenziswa ekuncediseni abantu emisebenzini yezinombolo.

ikhamanzi bz 5. BONA inkezo.

ikhambi bz 5. Ikhambi ngumuthi wokwelapha osetshenziswa ngabantu empilweni zabo zansuku zonke ongadingi sazi ukuthi uwuthole.

ikhambi bz 5. Ikhambi yisifo somzimba esiqubula umzimba ikakhulu ubuso.

ikhambi bz 5. Ikhambi licebo lokulungisa okonakeleyo.

ikhamera bz 5. Ikhamera ngumtshina wokuthatha amapikitsha.

ikhampani bz 5. Ikhampani liqembu labantu elisebenza ndawonye likhangele ngezamabhizimisi.

ikhampasi bz 5. Ikhampasi yithuluzi esetshenziswa ukudweba ikakhulu ezifundweni zenombolo.

ikhampasi bz 5. Ikhampasi ngumtshina okhombisa umuntu amagumbi omhlaba.

ikhanda bz 5. Ikhanda yisitho esiyinhloko yomuntu.

ikhandlela bz 5. Ikhandlela yisibane esingamafutha anqumileyo alentambo phakathi.

ikhangaru bz 5. Ikhangaru yinyamazana etholakala ikakhulu kwele Australia edume ngesikhwama sayo esingaphansi kwesisu ethwala ngaso abantwabayo.

ikhangarukhothi bz 5. Ikhangarukhoti ngumthethwandaba ongekho emthethweni ongenziwa yizibotshwa ejele, inhlanganiso yezisebenzi kumbe loba yiphi inhlanganiso ukuthonisisa elinye lamalunga alo eliyabe liphambanisile.

ikhango bz 5. Ikhango yinkomitsho enkulu.

ikhanka bz 5. Ikhanka yinyamazana yeganga elingana lenja edla izifuyo ezinjengembuzi.

\section{ikhasitadi}

ikhanophi bz 5. Ikhanophi lizenge elilibhokisi elembeswa ngemuva kwemota eyisigengele nxa kuvalelwa izulu, umoya kumbe ilanga.

ikhansili bz 5. Ikhansili ngabantu abakhethiweyo esigabeni kumbe endaweni abayabe bekhangele inhlupo kanye lentuthuko yaleyo ndawo.

ikhanzi bz 5. BONA ibhodo.

ikhaphakhapha bz 5. Ikhaphakhapha yinto enkulu njalo ebanzi.

ikhaphekhaphe bz 5. BONA ikhaphakhapha.

ikhaphelo bz 5. BONA idlelo.

ikhaphethi bz 5. Ikhaphethi yimethi enziwe ngentambo eziqinileyo eziconjwe zaba ngumbala okhangayo.

ikhaphithalizimu bz 5. Ikhaphithalizimu yindlela yempilo lapho umnotho oyabe usezandleni zabalutshwane abazama ukwenza inzuzo enengi kakhulu.

ikharadi bz 5. Ikharadi ngumuntu ozalwa ngabantu bembala eyehlukeneyo njengekhiwa lomuntu omnyama.

ikharathi [ikhalathi] bz 5. Ikharathi ngumdlalo wobuciko bokukhabana lokuzivikela ngezandla.

ikhasethi bz 5. Ikhasethi ngumcephe omncane olentambo lamavili amabili odlalwa erediyweni.

ikhasi bz 5. 1 Ikhasi yisembeso sesithelo kumbe esesilimo. 2 Ikhasi licele elilodwa elephepha egwalweni.

ikhasi bz 5. Ikhasi lihlamvu elomileyo.

ikhasi lenyoka bz 5. BONA inwebu.

ikhasi lenyoka bz 5. Ikhasi lenyoka yisikhumba senyoka esiphuma lapho inyoka ihluba.

ikhasili bz 5. Ikhasili ngumhlobo wotshwala bamambodlela.

ikhasimende bz 5. Ikhasimende ngumuntu ohlezi ethenga impahla yakhe emuntwini othile kumbe esitolo esithile aze azakale kulesositolo.

ikhasino bz 5. Ikhasino yindawo okuvunyelwa khona uzulu ukuthi abheje ngemali emitshineni lokuthi azithokozise.

ikhasitadi bz 5. Ikhasitadi yimputshana elithanga okuphekwa ngayo ilambazi lochago. 